\title{
STARR Operation in Management of Patients with Rectal Intussusception: Short Term Results
}

\author{
Mohamed Abdwahed, MD; Mohab G. Elbarbary, MD; Abd-Allah H. Ibrahim, MD \\ General Surgery Department, Ain Shams University, Cairo, Egypt
}

Aim: To evaluate the safety and efficacy of stapled transanal rectal resection (STARR), and its short -term outcomes (12- month) in patients with obstructive defectaion caused by rectal intussception.

Patients and methods: A prospective observational study was performed including 25 women with rectal intussusception who underwent STARR in the period from April 2017 to March 2018. Data were collected prospectively from standardized questionnaires for the assessment of constipation [constipation scoring system, Longo's obstructed defecation syndrome (ODS) score system, symptom severity score], patient satisfaction and quality of life (Patient Assessment of Constipation-Quality of Life Questionnaire).

Results: The preoperative status, perioperative and postoperative complications at baseline 3, 6 and 12 months were assessed. At a 12-months follow-up, a significant improvement in the constipation scoring system, ODS score system, symptom severity score, and quality of life was observed. The self-reported definitive outcome was excellent in $8(30 \%)$ patients, fairly good in $4(16 \%)$, good in $11(44 \%)$, and poor in $2(10 \%)$.

Conclusion: STARR can be performed safely without major morbidity and with very good short-term results in treating patients with obstructed defecation from rectal intussusception.

Key words: Stapled transanal rectal resection, Obstructed defecation syndrome (ODS), Rectal intussusceptions (RI).

\begin{abstract}
Introduction
Management and diagnosis of obstructed defecation syndrome (ODS) are still a big challenge for patients and surgeon. ${ }^{1}$ Obstructed defecation syndrome (ODS) is considered a complex and multifactorial condition which is more common in women than men as long as it has been estimated that approximately $20 \%$ of adult female population suffered from the syndrome. $^{2}$
\end{abstract}

ODS is characterized by the repeated urge to defecate with an impaired ability to evacuate the fecal bolus. ${ }^{3}$ Symptoms include unsuccessful fecal evacuation attempts, excessive straining, pain, bleeding after defecation, and a sense of incomplete fecal evacuation. Rectocele (herniation of the rectum into the vagina), internal rectal mucosal prolapse and rectal intussusceptions may be the cause of ODS. ${ }^{4}$ Genital prolapse, enterocele and non-relaxing puborectalis may also coexist as part of the syndrome. ${ }^{5}$ After Antonio Longo there are three potential surgical approaches in the management of disordered defecation in relation with internal rectal prolapse and rectocele including abdominal, transvaginal and transanal approaches. ${ }^{6}$ However, there is no method achieving overall superiority because of different patterns of complications and high rate of recurrence. ${ }^{7}$ The STARR procedure (stapled transanal rectal resection) belongs to the group of procedures performed through the anal canal (trans-anal approach). ${ }^{8}$
Based on the stapled hemorrhoidopexy procedure, it has been proposed as an alternative technique for patients with ODS caused by rectal intussusception (RI) called stapled trans-anal rectal resection (STARR). ${ }^{9}$ The novel technique is carried out sequentially using double circular stapler devices (PPH01, Ethicon Endo- Surgery), anteriorly and posteriorly, to restore normal rectal anatomy by strengthening rectovaginal septum and resecting redundant rectum. ${ }^{10}$ STARR has been implemented rapidly and described as an effective cure for RI, prolapsed hemorrhoids and even solitary rectal ulcer. ${ }^{11}$

\section{Patients and methods}

This prospective observational study was carried out in Ain Shams University hospitals. An informed consent was obtained from the patients for participation in this study. This assessment was approved by the Ethical Committee of the Faculty of Medicine, Ain Shams University.

From April 2017 to March 2018, 25 female patients with ODS caused by rectal intussception (RI) were presented at our colorectal clinic in Ain shams university hospitals with symptoms of obstructive defecation syndrome as repeated urge of defecation with failure of complete evacuation, excessive straining and anal pain. All patients were asked about other symptoms of ODS and previous histories of anorectal or gynecologic surgery. Apart from the 
comprehensive history, full clinical examination and colonoscopy, our patients underwent appropriate physiological investigations such as colonic transit time study defecography and anorectal manometry. All the patients had STARR operation by the same surgical team, using the original techniques without modifications.

\section{Inclusion criteria}

Patients with persistence of at least three specific ODS symptoms as (feeling of incomplete evacuation, frequent calls to defecate, prolonged painful straining, excessive toilet time, pelvic pain or pressure, rectal bleeding, soiling) Additionally, conservative treatment with diet $(2 \mathrm{~L} / \mathrm{d}$ water with high-fiber diet), laxatives (10 g/d lactulose), enemas and/or physiotherapy had been tried in all patients without success.

\section{Exclusion criteria}

Exclusion criteria were in accordance with the consensus statement published by the Pioneers group [4] and the consensus recommendations by wilson et al. ${ }^{12}$ These included patients with good response to conservative treatment, slow transit constipation, rectocele, enterocele, sigmoidocele, cystocele, genital prolapse, external rectal prolapse, pelvic floor dyssynergia, proctitis, active perineal infection, chronic diarrhoea, inflammatory bowel disease, neoplasia, anorectal stenosis and previous anterior resection with rectal anastomosis, and patients with anal incontinence (Cleveland Clinic Florida; Wexner Score > 7) and foreign material (such as mesh) adjacent to the rectum or with mental disorder. Furthermore, RI $<3 \mathrm{~cm}$ or RI $\geq 4$ $\mathrm{cm}$ on straining was not considered straightforward candidates for the STARR procedure. Also excluded were those with general contraindications for surgery and those who declined surgical treatment.

\section{Study design}

All patients had detailed data on preoperative status, perioperative and postoperative complications. A clinical assessment was performed immediately after surgery and at 3, 6, and 12 months apart from surgery. The magnitude and degree of ODS were quantified by Longo's ODS score system (Table 1) and the symptom severity (SS) score (Table 2). The summed global scores of ODS and SS range from 0-40 and 0-36, respectively, in which a higher score indicates more severe symptoms. Moreover, the index of patient satisfaction and quality of life was evaluated by Patient Assessment of ConstipationQuality of Life Questionnaire (PAC-QoL), a selfreported questionnaire, was used to measure the quality of life of patients. The validated PAC-QoL is composed of 28 items grouped into four subscales: physical discomfort, psychosocial discomfort, worries and concerns, and satisfaction. The first three subscales were used to assess the patient dissatisfaction index, with an overall score ranging from 0 to 96 (where lower scores correspond to better quality of life). The satisfaction subscale includes four items with a global score ranging from 0 to 16 , so that each patient's self-reported definitive outcome was defined as either poor (0-4), fairly good (5-8), good (9-12), or excellent (13-16) A new scoring system was given by Italian surgeon A. Longo who also devised STARR procedure for treatment of ODS. Original Longo score $(0-40)$ is 8 points scale (Defecation frequency, Straining, Sensation of incomplete evacuation, Recto/perineal pain/ discomfort, Activity reduction per week, Laxatives, Enemas, Digitation). Recently Longo modified this scoring system and added a lifestyle change parameters to seven symptoms based parameters. Currently Modified ODS (MODS) Longo score is the most commonly used scoring system to decide treatment strategy for ODS patients as well as to see percent and total change in ODS symptom score from baseline after intervention in short term and long term follow up trials at various intervals. ${ }^{13}$ Some authors have taken 9 as cut off score for intervention in ODS patients while others have taken 7as cut off point. There is no consensus till date on cut off score.

Table 2: Symptom severity score

\begin{tabular}{lccccc}
\hline Symptoms & None & $\begin{array}{c}\text { Very short } \\
\text { time }\end{array}$ & Some time & $\begin{array}{c}\text { Most of the } \\
\text { time }\end{array}$ & $\begin{array}{c}\text { All of the } \\
\text { time }\end{array}$ \\
\hline Need laxatives/enemas & 0 & 1 & 2 & 3 & 4 \\
Unsuccessful attempts to open bowels & 0 & 1 & 2 & 3 & 4 \\
Low frequency of bowel movements & 0 & 1 & 2 & 3 & 4 \\
Pain on opening bowels & 0 & 1 & 2 & 3 & 4 \\
Bleeding on bowel opening & 0 & 1 & 2 & 3 & 4 \\
Incomplete bowel opening & 0 & 1 & 2 & 3 & 4 \\
Increased time or straining to open bowels & 0 & 1 & 2 & 3 & 3 \\
Incontinence/soiling & 0 & 1 & 2 & & 3 \\
Difficulty to withstand urge to open bowels & 0 & 1 & & & 4 \\
\hline
\end{tabular}


Table 1: Longo's ODS score system

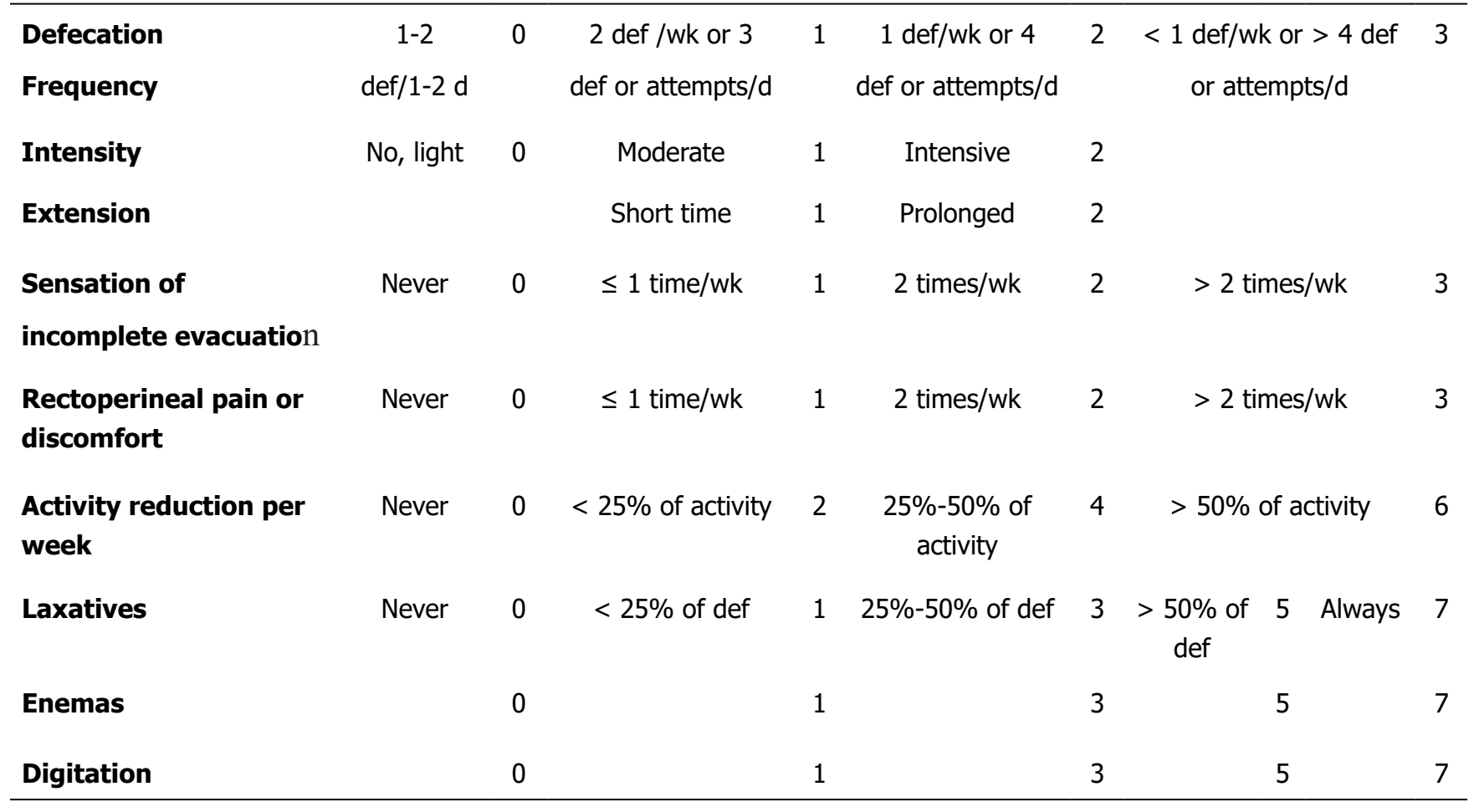

ODS: Obstructed defecation syndrome.

\section{Surgical technique}

A routine preoperative bowel preparation was done using Polyethylene glycol electrolyte solutions. Patients received broad-spectrum antibiotics immediately after the induction of anesthesia. The operation was always performed under spinal anesthesia with the patient in a lithotomy position. According to recommendations for the performance of STARR, two circular Covidien ${ }^{\mathrm{TM}}$ EEA $^{\mathrm{TM}}$ Hemorrhoid and Prolapse Stapler Set with DST Series ${ }^{\mathrm{TM}}$ Technology, a $33 \mathrm{~mm}$ diameter size with $3.5 \mathrm{~mm}$ staples as shown in (Figure 1) were used. Briefly, the anal canal was gently dilated, then the circular anal dilator was introduced and secured with silk sutures (Figure 2). Semi-circumferential purse-string sutures were positioned in the anterior rectum above the haemorrhoidal apex from 3 to 9 o'clock (Figure 3). The first stapler was inserted and the posterior rectal wall was protected with a spatula. The ends of sutures were delivered and tension was applied to prolapse the removed tissues into the stapler housing, making sure that the posterior vaginal wall had not been incorporated in female patient, the stapler was closed and fired (Figure 4). By the same procedure, two semicircumferential purse-string sutures and a second stapler were performed on the posterior rectal wall. Subsequent bleeding from the staple line was controlled with full-thickness 2-0 Vicryl ${ }^{\mathrm{TM}}$ stitches, and "posterior staple bridge" was divided with scissors.

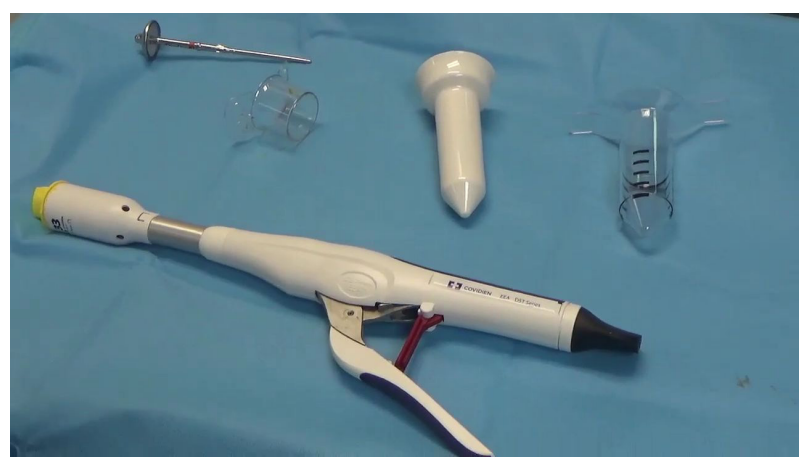

Fig 1: Covidien ${ }^{\mathrm{TM}}$ EEA $^{\mathrm{TM}}$ Hemorrhoid and Prolapse Stapler Set with DST Series ${ }^{\mathrm{TM}}$ Technology $33 \mathrm{~mm}$ diameter size with $3.5 \mathrm{~mm}$ staples.

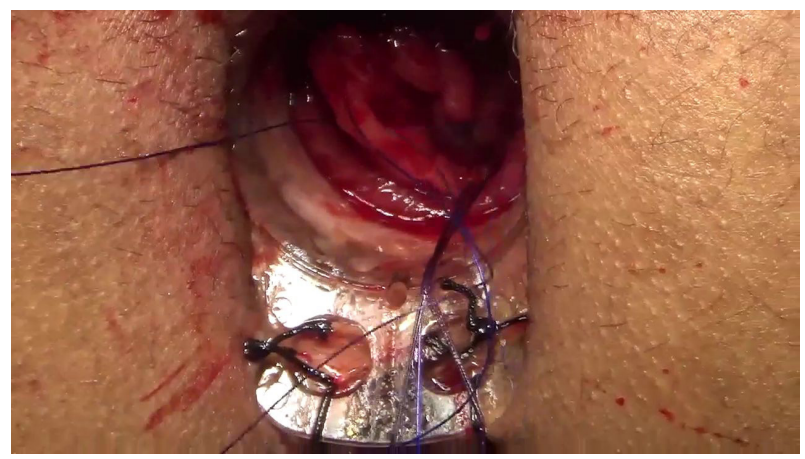

Fig 2: Secured circular anal dilator was introduced. 


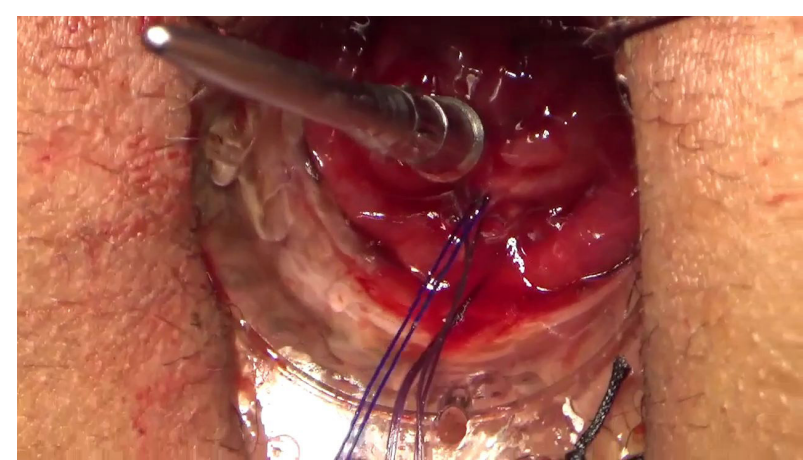

Fig 3: Purse string sutures were done around the anvel of stapler.

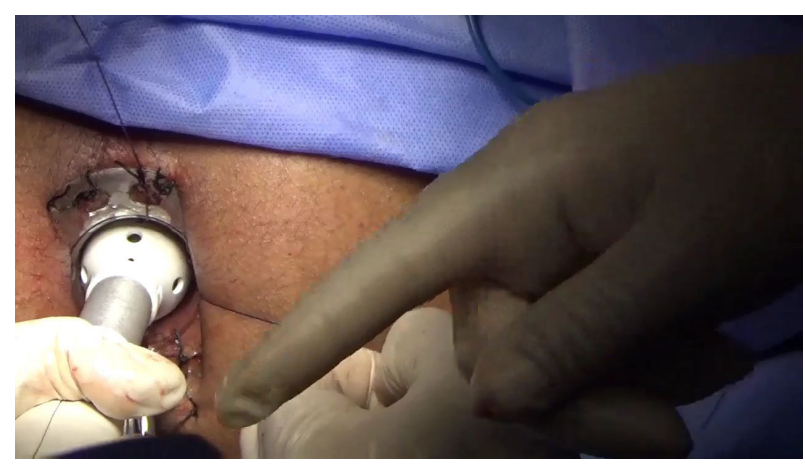

Fig 4: Circular anal stapler was introduced to encircle the anvil.

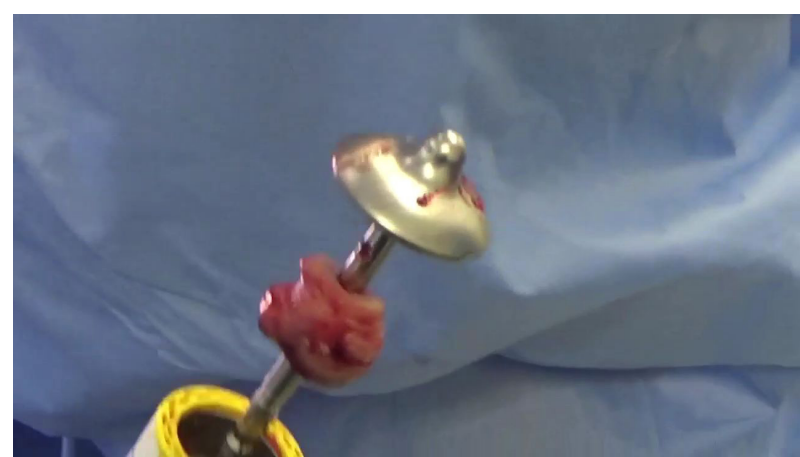

Fig 5: Full thickness donuts after resection.

\section{Results}

There were 25 female patients (median age 53.7 years (range, 30-70 years). As shown in Table 3 , $21(84 \%)$ patients had experienced 1-5 vaginal deliveries, 6 (24\%) had experienced at least one episiotomy, and 18 (68\%) had undergone prior anorectal or gynecologic surgeries. All the patients had symptoms of outlet obstruction (Table 4). Median operating time was 28 min (range, 20-50 min). The mean vertical height of the resected specimen was $3.8 \mathrm{~cm}$ (range, $2.5-4.8 \mathrm{~cm}$ ) anteriorly and $2.0 \mathrm{~cm}$ (range, $2.0-4.0 \mathrm{~cm}$ ) posteriorly; the mean horizontal length was $5.9 \mathrm{~cm}$ (range, 4.6$7.2 \mathrm{~cm}$ ) anteriorly and $4.4 \mathrm{~cm}$ (range, $3.2-5.3 \mathrm{~cm}$ ) posteriorly. The only intra-operative incident was subsequent bleeding from the anastomotic ring, which occurred in $92 \%$ of cases and was secured with hemostatic stitches.

Table 3: Previous anorectal or gynecologic surgery in patients undergoing STARR $\boldsymbol{n}(\%)$

\begin{tabular}{lcc}
\hline Operation & Number of Patients & Percentage (\%) \\
\hline Milligan-Morgan hemorrhoidectomy & 5 & 20 \\
Episiotomy & 7 & 28 \\
Abdominal delivery & 4 & 16 \\
lateral subcutaneous sphincterotomy & 1 & 4 \\
Hysterectomy & 1 & 4 \\
Fistulectomy & 1 & 4 \\
Stapled hemorrhoidopexy & 1 & 4 \\
\hline
\end{tabular}

Early complications are summarized in Table 4. The most common morbidity after surgery was defecatory urgency, and the incidence was $40 \%$ during the first postoperative week. Bleeding occurred in $3(12 \%)$ patients, but the symptoms were minor and were managed conservatively without further surgical intervention.
Other recorded complications were acute incontinence to flatus $(8 \%)$, severe pain $(8 \%)$ and anal fissure (4\%). No staple line dehiscence, massive rectal hemorrhage, rectovaginal fistula, perianal sepsis and postoperative mortality was occurred. 
Table 4: Presenting symptoms and early complications in patients undergoing STARR $\boldsymbol{n}(\%)$

\begin{tabular}{lccc}
\hline Symptoms & $\begin{array}{c}\text { Number of patients } \\
(\%)\end{array}$ & Early complications & Incidence \\
\hline Excessive straining & $22(88 \%)$ & Defactory urgency & $10(40 \%)$ \\
Feeling of incomplete evacuation & $23(92 \%)$ & Bleeding & $3(12 \%)$ \\
Rectal bleeding & $16(64 \%)$ & Incontinence to flatus & $2(8 \%)$ \\
Abdominal distention & $10(40 \%)$ & Severe pain & $2(8 \%)$ \\
Abdominal pain & $10(40 \%)$ & Anal fissure & $1(4 \%)$ \\
Feeling of rectal obstruction & $8(32 \%)$ & Rectovaginal fistula & 0 \\
Laxatives & $17(68 \%)$ & Perianal sepsis & 0 \\
Enemas & $10(40 \%)$ & Staple line dehiscence & 0 \\
Rectal or vaginal digitations & $8(32 \%)$ & Mortality & 0 \\
\hline
\end{tabular}

Table 5: Short-term follow up in patients undergoing STARR $n(\%)$

\begin{tabular}{lccc}
\hline Symptoms & $\mathbf{3}$ months & $\mathbf{6}$ months & $\mathbf{1 2}$ months \\
\hline Defecatory urgency & $6(24 \%)$ & $3(12 \%)$ & $1(4 \%)$ \\
Incontinence to flatus & $1(4 \%)$ & 0 & 0 \\
Incontinence to feces & 0 & 0 & 0 \\
Choronic pain & $2(8 \%)$ & $5(20 \%)$ & $1(4 \%)$ \\
Constipation & $5(20 \%)$ & 0 & $5(20 \%)$ \\
Rectal stenosis & 0 & 0 & 0 \\
\hline
\end{tabular}

In addition, the postoperative complications were followed up for one year. As shown in Table 5, the frequency of defecatory urgency decreased dramatically with time and was $24 \%$ at 3 -months, $12 \%$ at 6 -months and merely $1 \%$ at 12 -months follow-up. Incontinence to flatus was a problem in only 1 (4\%) elderly patient at a 3-month follow-up. Moreover, the patient was improved on regular 6months follow up. Another 2 (8\%) cases had chronic pain during 3-month after resection, whereas one resolved at a 6-mo follow-up. A Twenty (80\%) patients had a clinical benefit at 3 mo, however, constipation recurred in five patients at 6 months after the STARR procedure. At a follow-up of 12 months, the symptoms of constipation improved in $20(80 \%)$ patients. No rectal stenosis and rectal diverticulum occurred.

\section{Discussion}

ODS is still a challenging clinical problem, the pathophysiology of which remains not clearly defined. Rectal intussception (RI), however, is the most frequent anatomical defect associated with ODS. Although various surgical procedures had been described for the treatment of the syndrome, many of these were unsuitable for patients accompanied with RI. ${ }^{14-18}$ Until the development of the STARR technique, there was no surgical procedure for correction of ODS, and patients were treated conservatively with diet and biofeedback therapy and unfortunately, these trials was accompanied by high failure rate. In contrast to the transvaginal approach and perineal levatorplasty used to treat rectocele, the STARR procedure corrects both rectocele and rectal intussusceptions. Traditional operations in patients with rectal mucosal prolapse were associated with a high incidence of delayed healing of the perineal wound and dyspareunia. The combined endoanal and perineal approach increased the risk of sepsis due to fecal contamination and led to potentially fatal cases of pelvic gangrene. ${ }^{18}$

STARR has been demonstrated as an alternative operation and a relatively noninvasive surgical technique for ODS caused by RI. The STARR technique aims to resect internal rectal prolapse, restore anatomy, correct rectal volume consequently the function will be improved. ${ }^{19}$ However, it has been demonstrated that patient selection should be very careful because only symptomatic rectal intussusceptions justifies surgical treatment; other associated pathologies such as irritable colon or pudendal neuropathy are not modified by operation, so symptoms may persist ${ }^{20} \mathrm{~A}$ multicentric 
study done by Stuto et al. ${ }^{21}$ demonstrated that STARR procedure, for management of ODS, is technically simple to perform and able to revert all constipation symptoms; the operative time and hospital stay were short, the postoperative pain and bleeding were minimal, there were no sepsis or postoperative dyspareunia, and patients return early to work. Several studies confirm the safety and efficacy of the STARR procedure for management of ODS. ${ }^{22-24}$ Also, the data collected from this prospective clinical study suggest that $80 \%$ of our patients had satisfactory surgical results with improved symptoms of ODS with the STARR procedure, coupled with a few intraoperative and postoperative complications. The only intraoperative incident was bleeding from the staple line, which occurred in 23 (92\%) of patients, so the anastomotic ring should be meticulously checked and carefully secured with stitches whenever necessary. The most common early morbidity after surgery was defecatory urgency, and the incidence in our study was $40 \%$ during the first postoperative week which decreased to $24 \%$ after three-month follow-up. Other published studies have shown that defecatory urgency was the most common complaint in the immediate and intermediate recovery periods after STARR. ${ }^{24,25}$ Although the exact etiology of defecatory urgency is unclear, it may reflect the inflammatory response related to the staple line, presence of irritable rectum, and reduced rectal capacity or compliance. No major complications such as massive rectal hemorrhage and anastomotic line dehiscence occurred in our study. Few studies reported the incidence of severe complications such as staple line dehiscence, rectal diverticulum, pelvic infection, and even fulminating necrotizing pelvic fasciitis following the STARR procedure. ${ }^{26,27}$ Incontinence has been claimed to be a potential postoperative drawback of STARR; it may be a procedure-related complication caused by transient sphincteric impairment during instrumentation and anal dilatation. ${ }^{28-30}$ In this study, only one (4\%) elderly patient complained of incontinence to flatus during the first two weeks after the procedures and improved by time within 6 months of surgery. Our results confirmed that the rate of postoperative pain was low and there were no cases of dyspareunia. Also, Edward et al. ${ }^{31}$ in their prospective study concluded that STARR procedure is safe and effective, particularly in young females, due to the absence of complications related to the perineal levatorplasty and better results on postoperative pain, absence of dyspareunia, and better clinical outcome. Frascio et al. ${ }^{32}$ in their trial on 30 patients reported no mortality or pelvic sepsis and $4 \%$ of postoperative bleeding treated surgically, while in our study postoperative bleeding occurred in $3(12 \%)$ patients, but it was minor and stopped spontaneously with conservative treatment with no further surgical intervention required.
In our study, five (20\%) patients still had symptoms of ODS at 12-months postoperatively, and this may be due to persistence of excessive perineal descent therefore, it may be recommended to underwent abdominal rectopexy and follow up the results.

It is reasonable to suggest that the high percentage of successful results obtained, the short postoperative length of stay and the short time to return to work after the STARR procedure for management ODS would balance the relatively high cost of the procedure.

\section{Conclusion}

STARR represents a very good option in the surgical treatment of ODS caused by (RI) as it appeared to be safe and effective, with a successful short-term outcomes in most of the patients however longer follow-up period, more than 12 months, may be needed to assess long-term functional outcomes and symptomatic recurrence.

\section{References}

1. Kamm MA: Constipation. In: Nicholls RJ, Dozois $\mathrm{RR}$, editors. Surgery of the colon \& rectum. New York, NY, USA: Churchill Livingstone. 1997: 657-669.

2. Keighley MRB: Stipsi. In: Keighley MRB, Williams NS, editors. Chirurgia di Ano-Retto e Colon. Padova, Italy: Piccin. 2000: 615-644.

3. Regadas SMM, Regadas FSP, Rodrigues LV, Silva FR, Lima DMDR, Regadas-Filho FSP: Importance of the tridimensional ultrasound in the anorectal evaluation. Arquivos de Gastroenterologia. 2005; 42(4): 226-232.

4. Fritsch $\mathrm{H}$, Hotzinger $\mathrm{H}$ : Tomographical anatomy of the pelvis, visceral pelvic connective tissue, and its compartments. Clinical Anatomy. 1995; 8(1): 17-24.

5. Pinheiro Regadas FS, Murad Regadas SM, Rodrigues LV, et al: New devices for stapled rectal mucosectomy: a multicenter experience. Techniques in Coloproctology. 2005; 9(3): 243246.

6. Singh K, Cortes E, Reid WMN: Evaluation of the fascial technique for surgical repair of isolated posterior vaginal wall prolapse. Obstetrics and Gynecology. 2003; 101(2): 320-324.

7. Watson $\mathrm{SJ}$, Loder $\mathrm{PB}$, Halligan $\mathrm{S}$, Bartram $\mathrm{CI}$, Kamm MA, Phillips RKS: Transperineal repair of symptomatic rectocele with Marlex mesh: A clinical, physiological and radiologic assessment of treatment. Journal of the American College of Surgeons. 1996; 183(3): 257-261. 
8. Pescatori M, Favetta $\mathrm{V}$, Dedola $\mathrm{S}$, Orsini $\mathrm{S}$ : Stapled transanal excision of rectal mucosa prolapses. Tech Coloproctol. 1997; 1: 96-98.

9. Habr-Gama A, E Sousa AHS, Correia Roveló JM, et al: Stapled hemorrhoidectomy: Initial experience of a Latin American group. Journal of Gastrointestinal Surgery. 2003; 7(6): 809-813.

10. Nahas SC, Rodrigues Borba M, Teixeira Brochado MC, Sparapan Marques CF, Rizkallah Nahas CS, Miotto-Neto B: Stapled hemorrhoidectomy for the treatment of hemorrhoids. Arquivos de Gastroenterologia. 2003; 40(1): 35-39.

11. Sobrado CW, Cotti GCDC, Coelho FF, Da Rocha JRM: Initial experience with stapled hemorrhoidopexy for treatment of hemorrhoids. Arquivos de Gastroenterologia. 2006; 43(3): 238-242.

12. Wilson MS, Pope V, Doran HE, Fearn SJ, Brough WA: Objective comparison of stapled anopexy and open hemorrhoidectomy: A randomized, controlled trial. Diseases of the Colon \& Rectum. 2002; 45(11): 1437-1444.

13. Longo A: Treatment of hemorrhoidal disease by reduction of mucosa and hemorrhoidal prolapse with a circular suturing device: A new procedure. In: Proceedings of the $6^{\text {th }}$ World Congress of Endoscopic Surgery. 1998: 777-784.

14. Altomare DF, Rinaldi $M$, Veglia $A$, Petrolino $M$, De Fazio $M$, Sallustio $P$ : Combined perineal and endorectal repair of rectocele by circular stapler: A novel surgical technique. Diseases of the Colon \& Rectum. 2002; 45(11): 1549-1552.

15. Ayav A, Bresler L, Brunaud L, Boissel P: Longterm results of transanal repair of rectocele using linear stapler. Diseases of the Colon \& Rectum. 2004; 47(6): 889-894.

16. Renzi A, Izzo D, Di Sarno G, Izzo G, Di Martino $\mathrm{N}$ : Stapled transanal rectal resection to treat obstructed defecation caused by rectal intussusception and rectocele. International Journal of Colorectal Disease. 2006; 21(7): 661667.

17. Agachan F, Chen T, Pfeifer J, Reissman P, Wexner SD: A constipation scoring system to simplify evaluation and management of constipated patients. Diseases of the Colon \& Rectum. 1996; 39(6): 681-685.

18. Boccasanta P, Venturi M, Calabrò G, et al: Which surgical approach for rectocele? A multicentric report from Italian coloproctologists. Techniques in Coloproctology. 2001; 5(3): 149-156.

19. Boccasanta P, Venturi M, Stuto A, et al: Stapled transanal rectal resection for outlet obstruction: a prospective, multicenter trial. Diseases of the Colon \& Rectum. 2004; 47(8): 1296-1297.

20. Van Dam JH, Hop WC, Schouten WR: Analysis of patients with poor outcome of rectocele repair. Diseases of the Colon \& Rectum. 2000; 43(11): 1556-1560.

21. Stuto A, Boccasanta P, Venturi M, et al: Stapled transanal rectal resection (STARR) for obstructed defecation. A prospective multicentric trial. Annual Meeting Abstracts of American Society of Colon and Rectal Surgeons. Diseases of the Colon \& Rectum. 2000; 43, article A21.

22. Reboa G, Gipponi M, Logorio M, Marino P, Lantieri F: The impact of stapled transanal rectal resection on anorectal function in patients with obstructed defecation syndrome. Diseases of the Colon \& Rectum. 2009; 52(9): 1598-1604.

23. Arroyo A, González-Argenté FX, GarcíaDomingo $M$, et al: Prospective multicentre clinical trial of stapled transanal rectal resection for obstructive defaecation syndrome. British Journal of Surgery. 2008; 95(12): 1521-1527.

24. Jayne DG, Schwandner O, Stuto A: Stapled transanal rectal resection for obstructed defecation syndrome: One-year results of the european STARR registry. Diseases of the Colon \& Rectum. 2009; 52(7): 1205-1214.

25. Titu LV, Riyad K, Carter H, Dixon AR: Stapled transanal rectal resection for obstructed defecation: A cautionary tale. Diseases of the Colon \& Rectum. 2009; 52(10): 1716-1722.

26. Dodi G, Pietroletti R, Milito G, Binda G, Pescatori $\mathrm{M}$ : Bleeding, incontinence, pain and constipation after STARR transanal double stapling rectotomy for obstructed defecation. Techniques in Coloproctology. 2003; 7(3): 148153.

27. Pescatori M, Zbar AP: Reinterventions after complicated or failed STARR procedure. International Journal of Colorectal Disease. 2009; 24(1): 87-95.

28. Gagliardi G, Pescatori M, Altomare DF, et al: Results, outcome predictors, and complications after stapled transanal rectal resection for obstructed defecation. Diseases of the Colon \& Rectum. 2008; 51(2): 186-195. 
29. Binda GA, Pescatori M, Romano G, et al: The dark side of double-stapled transanal rectal resection. Diseases of the Colon \& Rectum. 2005; 48(9): 1830-1832.

30. Corman ML, Carriero A, Hager T, et al: Consensus conference on the stapled transanal rectal resection (STARR) for disordered defaecation. Colorectal Disease. 2006; 8(2): 98-101.

31. Ram E, Alper D, Atar E, Tsitman I, Dreznik
Z: Stapled transanal rectal resection: A new surgical treatment for obstructed defecation syndrome. Israel Medical Association Journal. 2010; 12(2): 74-77.

32. Frascio M, Stabilini C, Ricci B, et al: Stapled transanal rectal resection for outlet obstruction syndrome: results and follow-up. World Journal of Surgery. 2008; 32(6): 1110-1115. 